\title{
Correction: Inhibition of microRNA-384-5p alleviates osteoarthritis through its effects on inhibiting apoptosis of cartilage cells via the NF-KB signaling pathway by targeting SOX9
}

Weikai Zhang · Peng Cheng • Weihua Hu - Weifeng Yin · Fengjing Guo $\cdot$ Anmin Chen · Hui Huang

Published online: 29 July 2020

(C) The Author(s), under exclusive licence to Springer Nature America, Inc. 2020

Correction to: Cancer Gene Therapy

https://doi.org/10.1038/s41417-018-0029-y

The original version of this Article contained inaccuracies in Fig. 6b ("Sox9" band) and Fig. 8a ("mir-384-5p inhibitor" and "8 mir-384-5p inhibitor + sirna-sox9" groups). Both figures have been corrected in both the PDF and HTML versions of the Article. 
Fig. 6
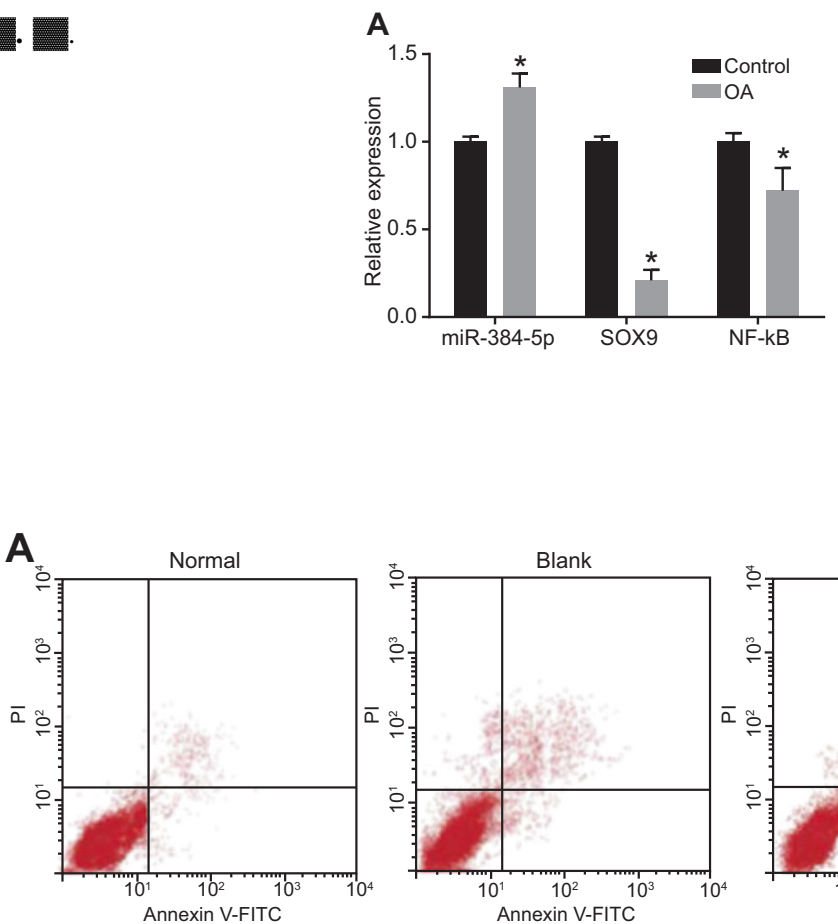

B

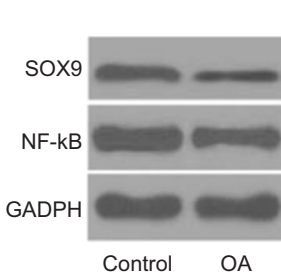

C

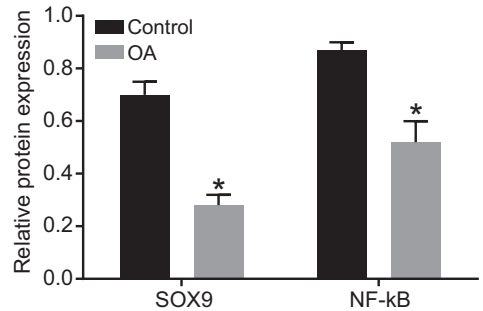

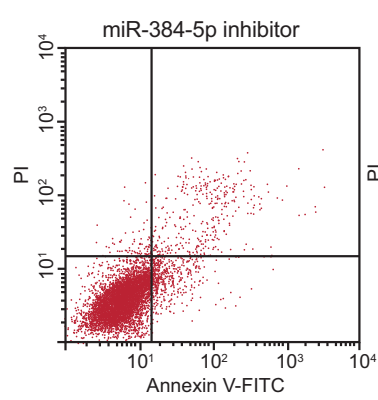
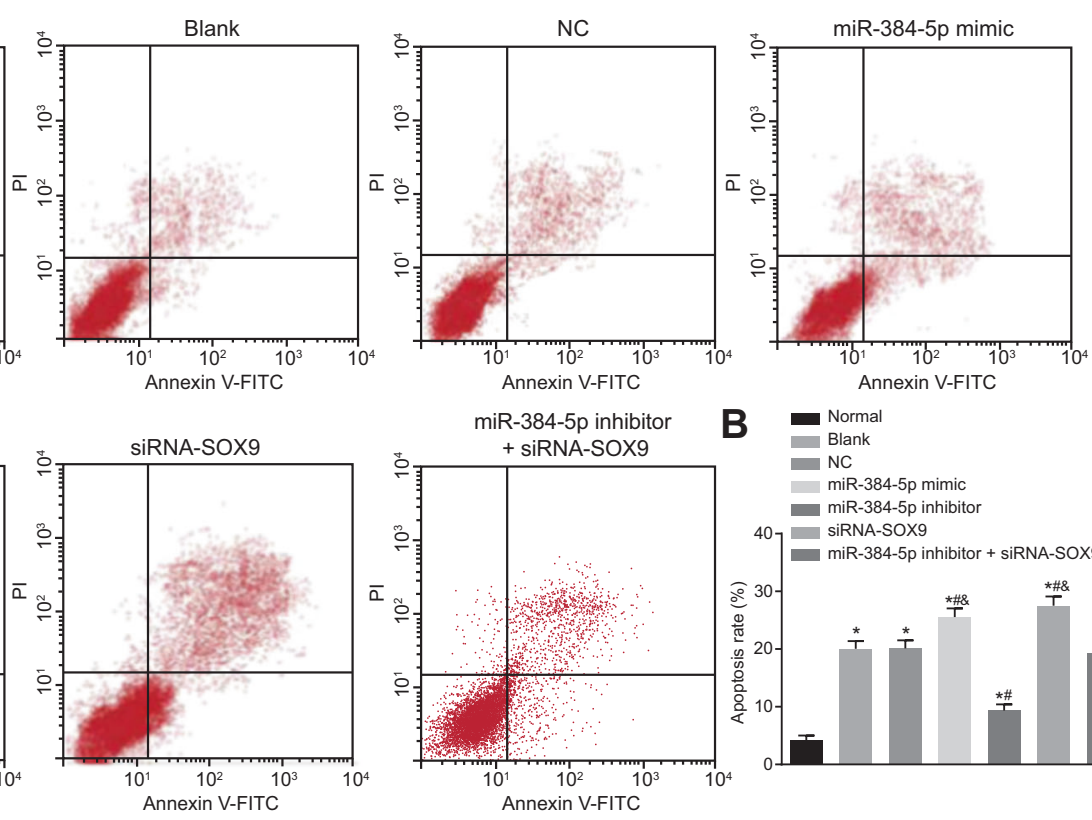

B $-\begin{gathered}\text { Normal } \\ \text { Blank }\end{gathered}$

NC

miR-384-5p mimic

miR-384-5p inhib
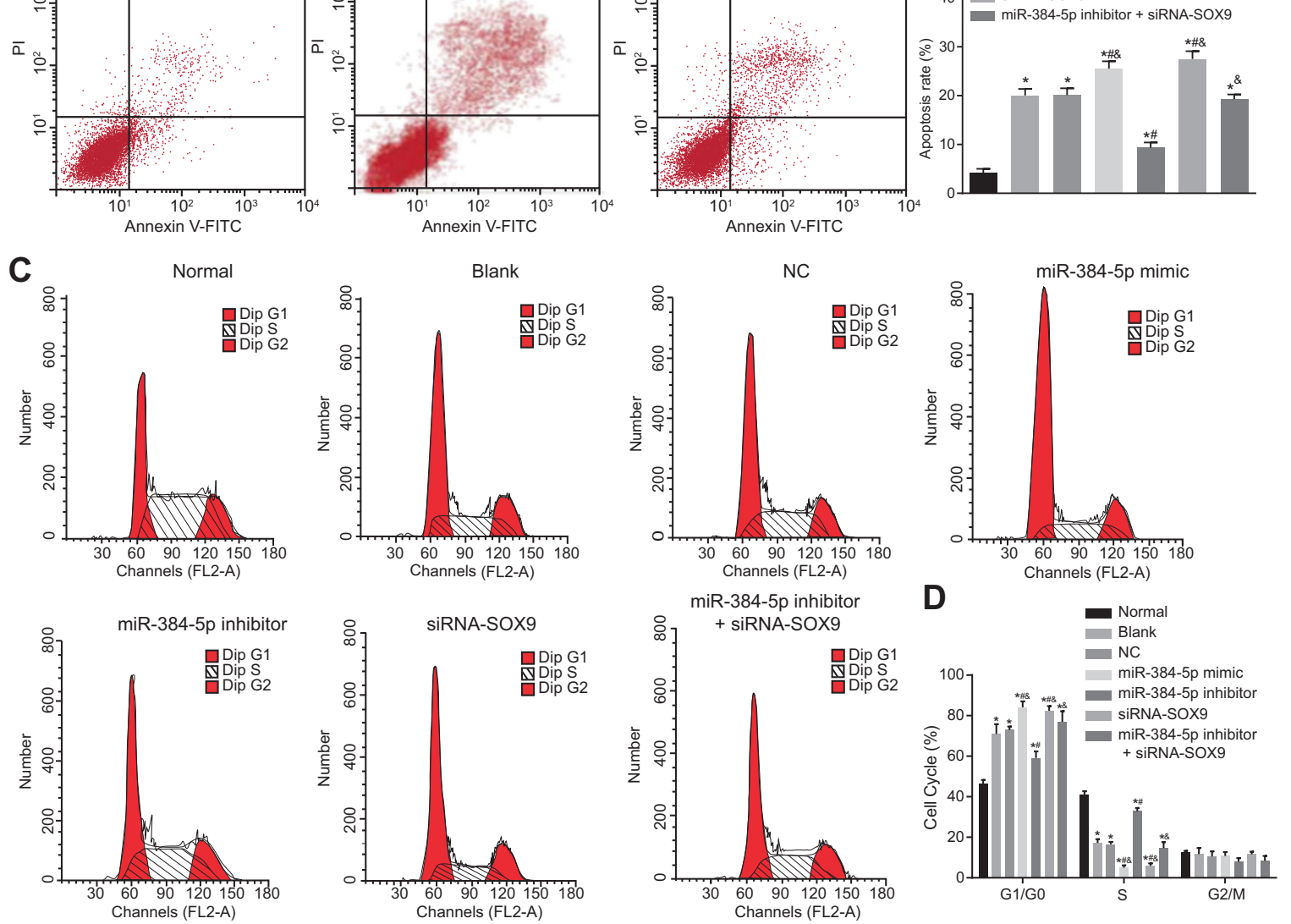

Fig. 8

8 를. 